\title{
PENGAMBILAN DATA SECARA BERGERAK PADA AUTOMATIC METER READING BERTOPOLOGI MESH
}

\author{
Fandisya Rahman ${ }^{1}$, Achmad Basuki², Ismiarta Aknuranda ${ }^{3}$ \\ 1,2,3 Fakultas Ilmu Komputer, Universitas Brawijaya \\ Email: ${ }^{1}$ rahmanfandi@student.ub.ac.id, ${ }^{2}$ abazh@ub.ac.id, ${ }^{3}$ i.aknuranda@ub.ac.id
}

(Naskah masuk: 12 Maret 2018, diterima untuk diterbitkan: 22 November 2018)

\begin{abstract}
Abstrak
Proses rekapitulasi informasi mengenai kuantitas pemakaian listrik, air, dan gas dari pelanggan perusahaan penyedia utilitas umumnya tersedia melalui proses pengumpulan data secara berkala. Proses pengumpulan/pencatatan data tersebut dilakukan oleh petugas yang berkunjung ke setiap rumah-rumah pelanggan secara periodik. Banyaknya rumah yang dikunjungi menyebabkan pekerjaan mencatat data menjadi berat dan memungkinkan terjadi kesalahan pencatatan. Data yang tidak akurat berkorelasi terhadap kerugian finansial yang ditanggung perusahaan penyedia utilitas. Berbagai teknologi untuk memudahkan pencatatan seperti (Automatic Meter Reading) AMR telah diterapkan, tetapi masih memiliki permasalahan dalam proses pengiriman data dari perangkat pencatat ke pusat basis data. Penelitian ini mengusulkan pengembangan teknologi AMR dengan menerapkan mekanisme pengambilan data secara bergerak dan nirkabel dengan topologi jaringan mesh. Setiap perangkat AMR diasumsikan sebagai perangkat statis yang terhubung secara topologi jaringan mesh dengan perangkat AMR lain yang saling berdekatan dan dapat bertindak sebagai relay untuk kemudian mengirimkan data ke perangkat pencatat bergerak yang digunakan oleh petugas atau disebut perangkat Mobile Data Gathering(MDG). Perangkat pencatat MDG dapat mengumpulkan data secara bergerak mendekati salah satu perangkat AMR untuk mengumpulkan data dari seluruh perangkat AMR yang saling berdekatan. Kecepatan bergerak perangkat pencatat AMR berpengaruh dalam akurasi pencatatan dan jumlah data yang dapat dikumpulkan. Berdasarkan hasil uji simulasi dapat diketahui bahwa sistem pengumpulan data dengan mekanisme bergerak mampu mengumpulkan data dengan kecepatan terbaik $30 \mathrm{~km} / \mathrm{jam}$ dengan jumlah data sebanyak $86 \%$ dari semua jumlah perangkat AMR.
\end{abstract}

Kata kunci: AMR, wireless mesh network, pengambilan data bergerak.

\section{Mobile Data Gathering on Automatic Meter Reading with Mesh Network}

\begin{abstract}
Recapitulation process information on the amount of electricity, water and gas from a utility provider of enterprise customers are generally available through periodic data gathering processes. The data gathering process mostly performed by officers who periodically visit each customers' house. The more number of houses to be visited, the heavier the workload for data recording and the recording errors may occur. Inaccurate data correlate with financial losses borne by utilities. Various techniques to facilitate the recording such as Automatic Meter Ready $(A M R)$ have been applied, but the problem during data transmission of data from the recording device to the central database still exists. This research proposes the development of AMR technology by applying the mechanism of wireless data transfer with mesh network topology. Each AMR device is assumed static devices in a network topology connected to other AMR devices side by side and can act as a relay than the data sent to a mobile agent recording device. The AMR wireless recording device can collect data that moves closer to one of the AMR devices to collect data from all neighboring AMR devices. The speed of movement of the AMR recording device affects the accuracy of the recording and the amount of data that can be collected. The evaluation results show that the data gathering system with a movement mechanism suitable for data collection at the best speeds of 30 $\mathrm{km} / \mathrm{h}$ with the successful data gathering around $86 \%$ of all AMR devices.
\end{abstract}

Keywords: AMR, mobile data gathering, wireless mesh network

\section{PENDAHULUAN}

Pada zaman modern ini, masyarakat memenuhi kebutuhan sehari-hari seperti air, listrik, dan gas, dengan berlangganan produk pemenuhan kebutuhan pada perusahaan penyedia utilitas. Informasi tentang jumlah konsumsi produk pelanggan menjadi sangat 
penting bagi perusahaan untuk menentukan biaya yang harus dibayar pelanggan. Di samping itu informasi konsumsi juga berguna untuk acuan dalam perencanaan pengembangan infrastruktur yang akan dibangun selanjutnya.

Informasi mengenai konsumsi produk oleh pelanggan diperoleh melalui proses pengumpulan data secara berkala. Kegiatan pengumpulan data dilakukan oleh petugas dengan datang ke setiap rumah pelanggan secara rutin. Petugas melakukan pencatatan pada perangkat meteran yang telah terpasang di setiap rumah pelanggan. Data yang telah dicatat dikumpulkan dan selanjutnya diberikan kepada perusahaannya.

Banyaknya rumah pelanggan yang dikunjungi petugas menyebabkan proses pengumpulan data menjadi berat dan hal ini juga meningkatkan peluang kesalahan petugas dalam mencatat data. Informasi yang tidak akurat menyebabkan kerugian pada perusahaan (Colak dkk, 2016). Kerugian yang dialami perusahaan akibat data yang tidak akuratnya data yaitu tidak tepatnya biaya yang dibayar pelanggan dan menyebabkan perencanaan tentang pengembangan perusahaan di masa depan menjadi kurang tepat, sehingga berakibat pada kerugian finansial yang pada perusahaan penyedia utilitas (Neto, 2015).

Teknologi yang digunakan untuk memudahkan proses pencatatan data yaitu dengan menerapkan (Automatic Meter Reading), tetapi sistem ini masih memiliki permasalahan dalam proses pengiriman data dari perangkat pencatat ke pusat basis data (Colak dkk, 2016). AMR adalah suatu sistem pencatat otomatis yang terdiri dari perangkat elektronik berbasis komputer. Data yang dicatat berupa kuantitas konsumsi pelanggan utilitas air, listrik dan gas. Pada umumnya data yang terkumpul berguna untuk menghitung jumlah tagihan pelanggan, prediksi konsumsi masa depan dan penanganan kerusakan (Khalifa, Naik \& Nayak, 2011).

Penelitian terkait pada pengembangan teknologi AMR antara lain melalui mekanisme komunikasi hop-to-hop antar AMR oleh (Yaacoub \& Abu-Dayya, 2014) (Cao, Tian \& Liu, 2008), menggunakan power line carrier (PLC) oleh (Zheng, Gao \& Lin, 2013)(Sivaneasan, Gunawan \& So, 2010) dan melalui layanan pesan singkat (SMS) oleh (Neto dkk, 2015)(Tan, Lee \& Mok, 2007)(Mohammad, Barua \& Arafat, 2013). AMR berbasis hop-to-hop dapat membentuk jaringan besar antar AMR tanpa hirarki, sehingga memungkinkan untuk pengiriman data hingga sampai pusat basis data. AMR berbasis PLC menggunakan jalur listrik yang terkait dengan data penggunaan utilitas dari setiap AMR ke pusat basis data. AMR berbasis SMS menggunakan layanan pesan singkat SMS yang diaktifkan dari masingmasing AMR untuk mengirimkan ke pusat basis data. Ketiga pendekatan yang ada memungkinkan pembacaan/pengumpulan data dari setiap AMR ke pusat basis data, akan tetapi masih memiliki kelemahan dari sisi waktu pengiriman, biaya, dan juga keandalan pengiriman data.

Penelitian ini mengusulkan pengembangan pada teknologi AMR dengan menerapkan mekanisme pengambilan data secara bergerak nirkabel dan jaringan bertopologi mesh. Mekanisme pengumpulan data secara bergerak didukung oleh sebuah perangkat yang memiliki fungsi khusus mengumpulkan data dengan cara bergerak yang disebut Mobile data gathering (MDG). Perangkat MDG melakukan pengumpulan data dengan cara berjalan mendekati perangkat AMR yang terpasang di rumah pelanggan. Perangkat MDG mengirimkan sebuah beacon permintaan secara periodik dan menunggu balasan dari perangkat AMR yang mendengar pesan permintaan ini. Perangkat AMR yang mendengar pesan permintaan dari perangkat MDG akan membalasnya dengan data konsumsi pelanggan. Perangkat MDG diasumsikan dibawa oleh petugas dalam melakukan perjalanan pengumpulan data. Saat petugas berada pada posisi yang dekat dengan rumah pelanggan, perangkat AMR yang telah terpasang di dalam rumah pelanggan akan mengirimkan data konsumsi pelanggan secara nirkabel menuju perangkat MDG yang dibawa oleh petugas. Dengan mekanisme ini petugas mampu memperoleh data konsumsi pelanggan tanpa harus memasuki setiap rumah, sehingga pekerjaan petugas menjadi lebih mudah dan cepat.

Perangkat MDG memiliki keterbatasan jalur dan posisi yang mampu dilewatinya, sehingga dimungkinkan adanya perangkat AMR yang letaknya terlalu jauh tidak didapatkan datanya. Permasalahan adanya perangkat AMR yang tidak terjangkau diatasi dengan topologi mesh nirkabel. Setiap perangkat AMR diasumsikan sebagai perangkat statis yang terhubung secara topologi jaringan mesh dengan perangkat AMR lain yang saling berdekatan dan dapat bertindak sebagai relay untuk kemudian mengirimkan data ke perangkat MDG. Penggunaan topologi mesh dipilih karena jarak antar rumah yang berdekatan (rapat dan mungkin sulit dijangkau secara fisik), tetapi setiap perangkat AMR berada dalam jangkauan perangkat komunikasi nirkabel perangkat tetangganya. Dengan situasi tersebut, perangkat AMR yang saling berdekatan dapat tergabung dalam sebuah jaringan bertopologi mesh.

Penelitian ini dilakukan dengan simulasi teknologi AMR dengan pengambilan data secara bergerak pada perangkat Automatic Meter Reading bertopologi mesh. Penelitian yang telah dilakukan oleh (Torres Neto, Guidoni \& Villas, 2015) menyatakan bahwa kecepatan perjalanan pengumpulan data berpengaruh terhadap kinerja komunikasi data. Pada kecepatan tinggi akan menimbulkan beberapa permasalahan komunikasi sehingga hanya mampu mengumpulkan sedikit pesan. Kecepatan paling optimal perlu diketahui agar sistem mampu mengumpulkan data dengan jumlah yang terbaik. Pengujian dilakukan dengan melakukan 
percobaan pengambilan data secara bergerak dengan beberapa variasi kecepatan yang berbeda untuk mengetahui kecepatan paling optimal dalam pengumpulan data. Evaluasi terhadap hasil pengujian dilakukan untuk mengetahui faktor yang paling berdampak terhadap jumlah dan ketepatan data yang dikumpulkan.

\section{METODE}

Ada dua sistem yang digunakan dalam penelitian ini, yaitu mekanisme pengambilan data secara bergerak atau Mobile Data Gathering (MDG) dan Automatic Meter Reading (AMR). Perangkat MDG dibawa berkeliling oleh petugas rekapitulasi data. Perangkat AMR terpasang di setiap rumah yang bekerja lebih pasif dengan mengirimkan data ketika perangkat MDG yang dibawa petugas datang melewatinya.

\subsection{Mekanisme Pengambilan Data Secara Bergerak}

Perangkat Mobile Data Gathering (MDG) adalah sebuah perangkat yang berfungsi untuk mengumpulkan data pada Automatic Meter Reading (AMR) dengan cara bergerak mendekatinya. Perangkat MDG dan AMR dilengkapi dengan perangkat radio jarak pendek. Dengan adanya perangkat radio pada masing-masing alat tersebut, memungkinkan keduanya berkomunikasi untuk mengirimkan data. Perangkat MDG mengirimkan sinyal permintaan kepada AMR secara berkala dan terus menerus selama perjalanan pengambilan data. Perangkat MDG akan mengirimkan sinyal permintaan kepada perangkat AMR, ketika perangkat AMR mendapat sinyal permintaan membalasnya dengan mengirimkan data hasil pembacaan pemakaian utilitas. AMR mempunyai transmitter range sejauh 20 meter. Mekanisme kerja MDG dapat dilihat lebih jelas pada Gambar 1.

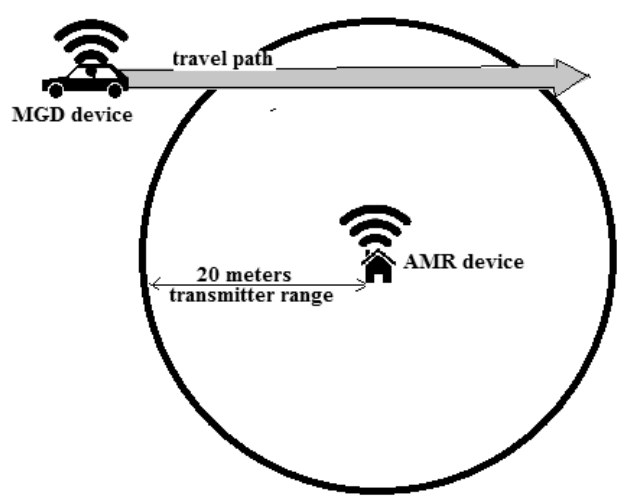

Gambar 1. Pengambilan data secara bergerak menggunakan perangkat MDG

Seperti yang dijelaskan sebelumnya, bahwa perangkat AMR dipasang pada setiap rumah untuk memudahkan pengiriman data. AMR akan dipasang dengan topologi tertentu untuk melihat kecepatan dan keakuratan dalam pengiriman data. Gambaran peletakan perangkat AMR pada setiap rumah dan proses pengambilan data oleh MDG ditunjukkan pada Gambar 2.

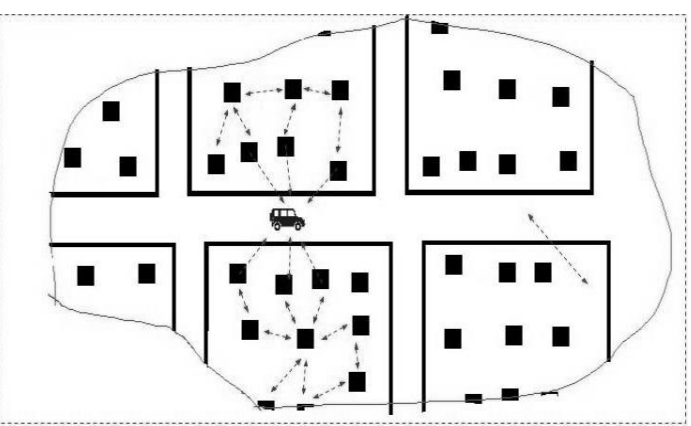

Gambar 2. Pengambilan data secara bergerak

Pada Gambar 2 simbol mobil mewakili perangkat MDG yang sedang berjalan untuk melakukan proses pengumpulan data pada perangkat AMR yang terpasang di setiap rumah pelanggan. Gambar persegi hitam mewakili perangkat AMR yang terpasang di setiap rumah pelanggan. Perangkat MDG berjalan melawati jalan pemukiman sambil mengirimkan sinyal permintaan secara terus menerus. Setiap perangkat AMR yang mendapat sinyal permintaan akan membalasnya dengan mengirimkan data hasil pembacaan meteran kepada MDG yang sedang lewat.

\subsection{AMR Dengan Topologi Mesh}

Perangkat pengumpul data (MDG) memiliki keterbatasan yaitu rute yang dilewati terbatas tidak semua jalan mampu dilalui oleh petugas pembawa MDG. Sebagian dari perangkat AMR terletak terlalu jauh sehingga tidak terjangkau oleh perangkat pengumpul data (MDG). Mekanisme saling berbagi data digunakan untuk mengatasi masalah ini. Setiap perangkat AMR menyimpan data tetangganya untuk membantu perangkat AMR yang letaknya terlalu jauh untuk mengirimkan data menuju perangkat MDG. Topologi mesh memungkinkan perangkat AMR saling berbagi data dengan perangkat tetangganya, sehingga masing-masing perangkat AMR juga menyimpan data milik tetangganya.

Pada mekanisme saling berbagi data memiliki kemungkinan terjadinya duplikasi data yang disebabkan oleh dua perangkat AMR yang berdekatan menyimpan data yang sama. Jika kedua perangkat sama-sama mengirimkan data ke perangkat pengumpul data MDG, maka akan menyebabkan duplikasi data. Namun, walaupun terjadi duplikasi tetapi memiliki keuntungan yaitu perangkat MDG mampu memperoleh data dari perangkat AMR yang posisinya di luar jangkauan sehingga jumlah keseluruhan data unik juga menjadi lebih banyak. 


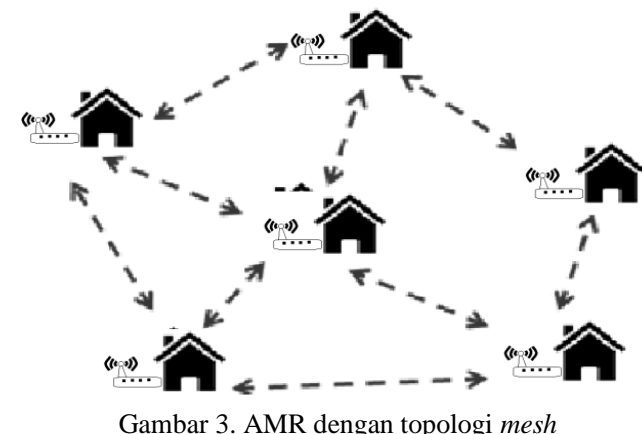

Gambar 3 menunjukkan bahwa setiap perangkat AMR saling terhubung dengan perangkat AMR lainya dan secara periodik perangkat AMR berbagi data dengan perangkat AMR terdekatnya, sehingga setiap dari perangkat AMR menyimpan data dari tetangganya.

\subsection{Rancangan alat}

Mekanisme pengumpulan data secara bergerak terdiri dari dua perangkat yaitu Automatic Meter Reading $(A M R)$ yang berfungsi membaca dan menyimpan data pemakaian konsumsi pelanggan dan perangkat Mobile Data Gathering (MDG) yang berfungsi mengumpulkan data dengan mekanisme bergerak.

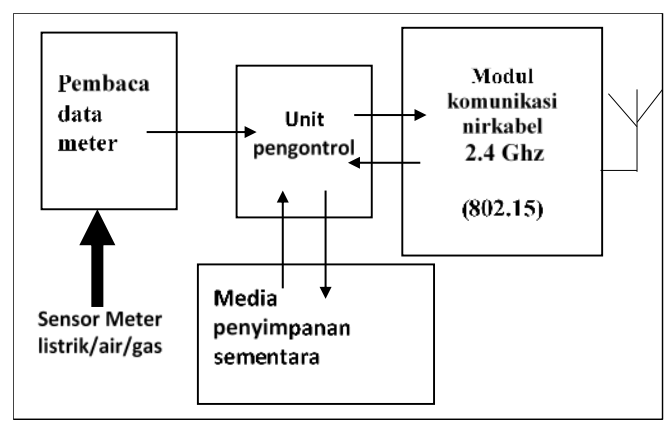

Gambar 3. Perangkat automatic meter reading (AMR)

Gambar 3 adalah skema prototipe dari perangkat AMR. Perangkat ini terdiri dari unit pengontrol, media penyimpanan sementara, sensor meter dan modul komunikasi nirkabel berfrekuensi $2.4 \mathrm{GHz}$. modul sensor meter berfungsi menghitung kuantitas pemakaian pelanggan. Data hasil pembacaan disimpan dalam media penyimpanan sementara. Modul komunikasi nirkabel berfungsi mengirimkan data yang tersimpan dalam media penyimpanan sementara menuju perangkat MDG. Perangkat komunikasi nirkabel juga memiliki fungsi berkomunikasi dengan tetangga terdekat untuk saling berbagi data utilitas.

Gambar 4 Adalah skema perangkat MDG yang berfungsi sebagai perangkat pengumpul data dengan mekanisme bergerak. Pada perangkat MDG juga dilengkapi dengan modul komunikasi nirkabel dengan frekuensi $2.4 \mathrm{GHz}$ dan standar 802.15 untuk memungkinkan saling bertukar data.

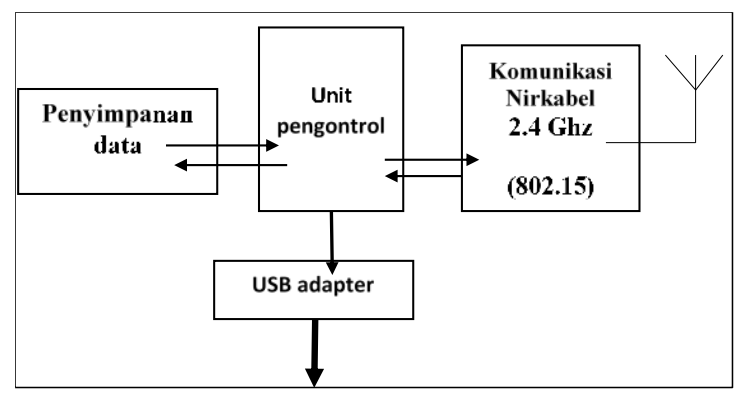

Gambar 4. Mobile data gathering (MDG)

Dengan modul nirkabel perangkat MDG mampu mengirimkan sinyal permintaan dan menerima data hasil pembacaan data pelanggan dari perangkat AMR. Perangkat MDG juga dilengkapi dengan media penyimpanan data untuk menampung data hasil pembacaan AMR.

\subsection{Mekanisme komunikasi perangkat MDG}

Perangkat pengumpul data yang bergerak tidak mampu menerima data lebih dari satu perangkat AMR secara bersamaan maka dari itu setiap perangkat AMR mengirimkan data secara bergantian sesuai dengan slot (alokasi) waktu. Ketika perangkat bergerak mengirimkan sinyal permintaan, setiap perangkat AMR yang menerima permintaan akan melakukan pengacakan nomor untuk menentukan slot waktu untuk mengirimkan data.

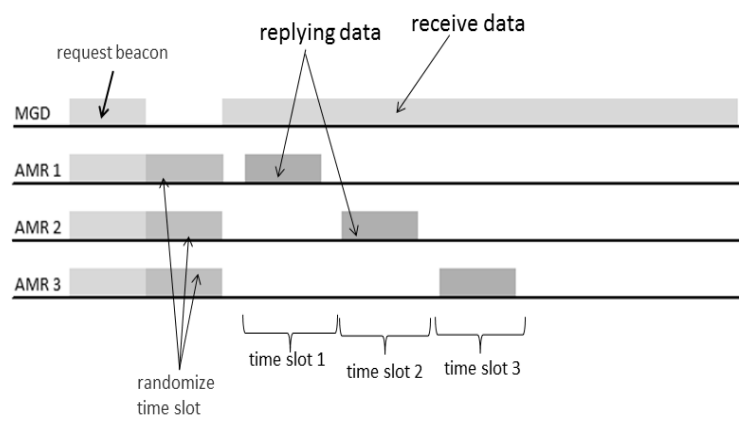

Gambar 5. Diagram alokasi waktu komunikasi perangkat

Pada gambar 5 ditunjukkan urutan waktu dari proses komunikasi antara MDG dan AMR. Secara periodik MDG yang dilengkapi perangkat radio berbasis 802.15 dengan frekuensi $2,4 \mathrm{GHz}$ akan mengirimkan sinyal beacon permintaan sambil berjalan, dan setiap perangkat AMR yang mendengarnya akan membalas sinyal dengan data hasil pembacaan meteran. Mekanisme pengacakan waktu dilakukan untuk menghindari tabrakan dalam komunikasi data antar perangkat AMR dan perangkat MDG. Setiap perangkat AMR yang menerima sinyal permintaan dari MDG akan melakukan pengacakan waktu dan mengirimkan data hasil pembacaan secara bergantian sesuai dengan alokasi waktu yang telah ditentukan secara acak. 


\section{SIMULASI}

Pengujian dengan variasi kecepatan yang berbeda dilakukan untuk mengetahui kecepatan perjalanan paling optimal dalam pengumpulan data. Pengumpulan data dengan kecepatan yang tinggi lebih hemat waktu tetapi menimbulkan permasalahan komunikasi antar perangkat. Permasalahan pada komunikasi menyebabkan berkurangnya data yang mampu dikumpulkan. Pengujian pada penelitian ini dilakukan dengan membuat model simulasi pengambilan data dengan mekanisme bergerak. Perangkat MDG disimulasikan melakukan perjalanan pengumpulan data dengan kecepatan yang berbeda secara berulang-ulang.

Tabel 1. Skenario simulasi

\begin{tabular}{|c|c|}
\hline \multicolumn{2}{|c|}{ skenario simulasi } \\
\hline jumlah perangkat AMR & 200 perangkat \\
\hline jumlah blok AMR & $\begin{array}{l}4 \text { blok masing-masing } 50 \\
\text { perangkat }\end{array}$ \\
\hline $\begin{array}{c}\text { perkiraan jarak antar } \\
\text { AMR }\end{array}$ & 1 - 20 meter \\
\hline kepadatan perangkat & 50 perangkat / sekian meter \\
\hline $\begin{array}{c}\text { kecepatan pengambilan } \\
\text { data }\end{array}$ & $10-60 \mathrm{~km} / \mathrm{jam}$ \\
\hline $\begin{array}{c}\text { jumlah percobaan / } \\
\text { kecepatan }\end{array}$ & $\begin{array}{l}20 \text { kali perjalanan / } \\
\text { kecepatan }\end{array}$ \\
\hline
\end{tabular}

Tabel 1 menjelaskan skenario Dalam simulasi proses pengambilan data dengan mekanisme bergerak. Proses pengambilan data dilakukan sebanyak 120 kali perjalanan yang terdiri dari 6 kecepatan yang berbeda. Setiap kecepatan diuji dengan melakukan 20 kali perjalanan. Jarak antar perangkat AMR diasumsikan memiliki nilai tidak seragam dengan variasi antara 1 - 20 meter. Jarak antar perangkat AMR ditentukan dengan pembangkitan acak pada rentang nilai acak $1-20$. Kecepatan perangkat MDG saat berjalan mengumpulkan data adalah $10 \mathrm{~km} / \mathrm{jam}-60 \mathrm{~km} / \mathrm{jam}$ dengan kenaikan kecepatan $10 \mathrm{~km} / \mathrm{jam}$. Kecepatan dalam simulasi ditentukan berdasarkan asumsi kecepatan umum kendaraan pembawa perangkat MDG. Pengujian dilakukan dengan melakukan beberapa proses perjalanan. Setiap perjalanan dilakukan dengan kecepatan yang berbeda dan dicatat jumlah data yang mampu dikumpulkan dalam sekali perjalanan. Jangkauan radio dari perangkat MDG dan perangkat AMR yaitu 20 meter.

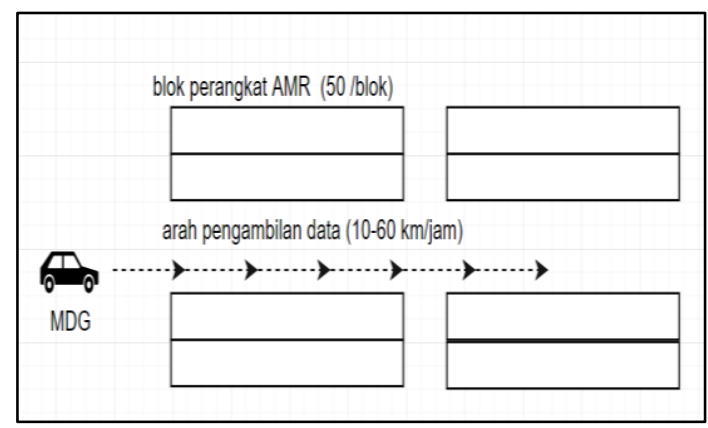

Gambar 6. Skenario simulasi pengambilan data secara bergerak
Gambar 6 menunjukkan gambaran simulasi bagaimana perangkat MDG melakukan proses pengumpulan data pada sekumpulan AMR yang tersusun posisinya. Perangkat AMR disusun menjadi dua baris yang terdiri dari 4 blok atau kumpulan. Setiap kumpulan yang membentuk blok AMR dibatasi oleh jalan. pada satu area blok AMR terdiri dari 50 perangkat AMR Perangkat MDG atau pengumpul data berjalan melewati ruang kosong di antara blok yang disediakan untuk jalan. Kecepatan MDG ketika proses pengambilan data berkisar di antara $10-60 \mathrm{~km} / \mathrm{jam}$.

\section{HASIL DAN PEMBAHASAN}

Berdasarkan hasil pengujian simulasi maka diketahui jumlah rata-rata informasi meteran AMR yang mampu dikumpulkan MDG. Data yang diperolah dari simulasi terdiri dari jumlah data AMR yang terkumpul dengan topologi mesh, jumlah data terkumpul tanpa menggunakan topologi mesh, dan duplikasi pada keduanya. Kumpulan data yang diperoleh dari hasil simulasi menunjukkan hubungan antara kecepatan terhadap jumlah data yang mampu dikumpulkan dengan rute perjalanan yang sama. Informasi jumlah data yang mampu dikumpulkan ditunjukkan pada gambar 6

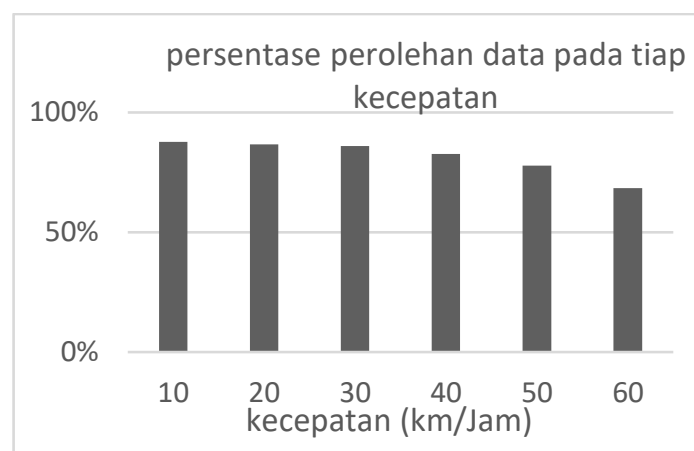

Gambar 7. persentase jumlah data meter terbaca MDG per kecepatan dengan topologi mesh

Gambar 7 adalah diagram yang menunjukkan pengaruh kecepatan terhadap jumlah data yang mampu dikumpulkan. Semakin cepat perangkat MDG bergerak maka semakin sedikit data yang mampu dikumpulkan MDG. Hal yang menyebabkan berkurangnya data yang diperoleh ketika MDG menambah kecepatannya yaitu karena proses pertukaran data antar perangkat AMR menuju MDG membutuhkan waktu. Jika waktu yang dibutuhkan untuk mengirimkan data dari perangkat AMR menuju MDG lebih lama daripada waktu ketika perangkat MDG berada pada posisi yang tepat, maka data akan gagal terkirim. Gagalnya pengiriman data disebabkan karena perangkat MDG sudah berjalan terlalu jauh dari perangkat AMR yang ingin mengirimkan data.

Pengujian dilakukan untuk mengetahui kesesuaian antara kecepatan dan jumlah data yang diperoleh, sehingga kecepatan dalam proses pengumpulan data tidak terlalu lambat tetapi data 
yang dikumpulkan juga tidak terlalu sedikit. Sistem di asumsikan dapat berjalan dengan baik apabila data yang mampu di kumpulan lebih dari $80 \%$ dari total jumlah perangkat AMR. Berdasarkan gambar 6 dapat diketahui bahwa sistem mampu mengumpulkan data di atas $80 \%$ pada kecepatan $10-40 \mathrm{~km} / \mathrm{jam}$. Kecepatan terbaik proses pengumpulan data yaitu $30 \mathrm{~km} / \mathrm{jam}$ karena pada kecepatan ini hasil data yang didapatkan tidak jauh berbeda kecepatan 10 dan $20 \mathrm{~km} / \mathrm{jam}$.

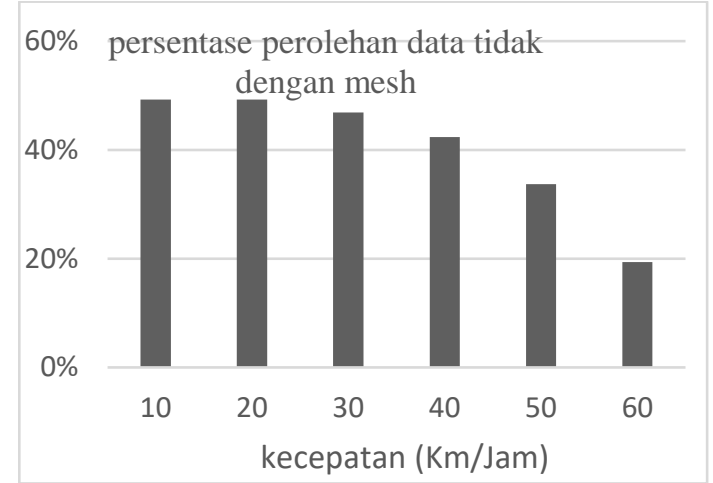

Gambar 8 persentase jumlah data meter terbaca MDG per kecepatan tanpa topologi mesh.

Gambar 8 adalah persentase dari rata-rata jumlah data AMR yang mampu dikumpulkan tanpa menggunakan topologi mesh. Pada sistem ini, data yang dikumpulkan MDG lebih sedikit dan kurang dari 50\% dari perangkat AMR. Penyebab kurangnya data yang terkumpul adalah terbatasnya posisi yang mampu dilalui perangkat MDG. Perangkat AMR yang letaknya terlalu jauh dari MDG tidak mampu mengirimkan pesan menuju perangkat MDG. Pemanfaatan mekanisme berbagi data dengan topologi mesh menjadi penting agar perangkat AMR yang letaknya terlalu jauh dapat menitipkan data hasil pembacaan meteran kepada perangkat AMR lain yang letaknya berada dalam jangkauan MDG.

\begin{tabular}{cc}
\multicolumn{2}{c}{ Tabel 2. Duplikasi data } \\
\hline $\begin{array}{c}\text { Kecepatan } \\
\text { (km/jam) }\end{array}$ & Duplikasi \\
\hline 10 & 1319 \\
20 & 933 \\
30 & 569 \\
40 & 354 \\
50 & 214 \\
60 & 131 \\
\hline
\end{tabular}

Tabel 2 menunjukkan adanya duplikasi yang ditimbulkan ketika proses pengumpulan data. Mekanisme berbagi data memungkinkan perangkat AMR membagikan data kepada lebih dari satu perangkat tetangga. Dua perangkat tetangga yang menyimpan data yang sama menimbulkan duplikasi pada perangkat MDG ketika keduanya sama-sama mengirimkan datanya menuju perangkat MDG.
Berdasarkan hasil simulasi diketahui bahwa kecepatan terbaik dalam pengumpulan data yaitu 30 $\mathrm{km} / \mathrm{jam}$ dengan jumlah data yang mampu dikumpulkan sebanyak $86 \%$. Pada kecepatan 10 dan $20 \mathrm{~km} / \mathrm{jam}$ sistem mampu mengumpulkan data lebih banyak, tetapi memiliki selisih yang tidak terlalu jauh. Sehingga di asumsikan kecepatan $30 \mathrm{~km} / \mathrm{jam}$ adalah kecepatan paling baik dalam proses pengumpulan data.

Implementasi mekanisme berbagi data memanfaatkan topologi mesh memiliki pengaruh dalam peningkatan jumlah data yang mampu dikumpulkan MDG. Perangkat MDG mampu mengumpulkan data dengan rata-rata $81 \%$ pada sistem bertopologi mesh. Pada perangkat tanpa topologi mesh perangkat MDG hanya mampu mengumpulkan data dengan rata-rata $40 \%$.

Pemanfaatan topologi mesh pada sistem pengambilan data dengan mekanisme bergerak juga menyebabkan masalah duplikasi data, Tetapi masalah duplikasi data ini juga diikuti dengan meningkatnya data unik yang mampu dikumpulkan. Pada pengembangan teknologi selanjutnya, permasalahan duplikasi data dapat dikurangi dengan adanya metode filtering dan perbaikan dalam algoritma komunikasi.

\section{DAFTAR PUSTAKA}

CAO, L., JIANG, W. dan ZHANG, Z., 2008. Networked wireless meter reading system based on ZigBee technology. Chinese Control and Decision Conference, 2008, CCDC 2008, pp.3455-3460.

CAO, L., TIAN, J. AND LIU, Y., 2008. Remote Wireless Automatic Meter Reading System Based on Wireless Mesh Networks and Embedded Technology. pp.192-197.

COLAK, I., SAGIROGLU, S., FULLI, G., Yesilbudak, M. and Covrig, C.F., 2016. A survey on the critical issues in smart grid technologies. Renewable and Sustainable Energy Reviews.

KHALIFA, T., NAIK, K. dan NAYAK, A., 2011. A survey of communication protocols for automatic meter reading applications. In: IEEE Communications Surveys and Tutorials. pp.168-182.

MOHAMMAD, N., BARUA, A. dan ARAFAT, M.A., 2013. A smart prepaid energy metering system to control electricity theft. In: Proceedings of 2013 International Conference on Power, Energy and Control, ICPEC 2013.

NETO, J.R.T., YOKOYAMA, R.S., Boukerche, A., Guidoni, D.L., Meneguette, R.I. and Villas, L.A., 2015. Towards the use of unmanned aerial vehicles for automatic power meter readings. Proceedings - 15th IEEE International Conference on Computer and Information Technology, CIT 2015, 14th IEEE International Conference on 
Ubiquitous Computing and

Communications, IUCC 2015, 13th IEEE

International Conference on Dependable,

Autonomic and Se, pp.379-386.

SIVANEASAN, B., GUNAWAN, E. dan SO, P.L., 2010. Modeling and performance analysis of automatic meter-reading systems using PLC under impulsive noise interference. IEEE Transactions on Power Delivery, 25(3), pp.1465-1475.

TAN, H.G.R., LEE, C.H.R. AND MOK, V.H., 2007. Automatic power meter reading system using GSM network. 2007 International Power Engineering Conference (IPEC 2007), pp.465-469.

TORRES NETO, J.R., GUIDONI, D.L. dan VILLAS, L.A., 2015. A Lightweight Solution to perform Automatic Meter Reading using an Unmanned Aerial Vehicle. IEEE Latin America Transactions, 13(3), pp.628-633.

YAACOUB, E. dan ABU-DAYYA, A., 2014. Automatic meter reading in the smart grid using contention based random access over the free cellular spectrum. Computer Networks, [online] 59, pp.171-183. Available at: $<$ http://dx.doi.org/10.1016/j.bjp.2013.10.009 $>$.

ZHENG, J., GAO, D.W. dan LIN, L., 2013. Smart meters in smart grid: An overview. In: IEEE Green Technologies Conference. 
Halaman ini sengaja di kosongkan 